\title{
POR UM ESPAÇO (PRIVILEGIADO) DOS ESTUDOS DA TRADUÇÃO NA FORMAÇÃO DO LICENCIANDO EM LETRAS
}

\section{IN SEARCH FOR A PRIVILEGED SPACE OF TRANSLATION STUDIES IN THE UNDERGRADUATE STUDENT TRAINING}

\author{
Silvana Ayub Polchlopek \\ Universidade Tecnológica Federal do Paraná \\ Curitiba, Paraná, Brasil \\ Flávia Azevedo \\ Universidade Tecnológica Federal do Paraná \\ Curitiba, Paraná, Brasil
}

RESUMO: Historicamente ancorada nos resquícios do método gramática-tradução, a atividade tradutória sempre foi vista como um desvio no caminho para a fluência na língua em estudo. Porém, a tradução nunca foi, nem deve ser entendida como metodologia de ensino, mas sim como ferramenta no processo de conhecimento e uso da língua. Nesse sentido, discutir a tradução nos cursos de licenciatura em Letras, que abordam processos de leitura e escrita como parte do processo de aquisição de línguas, torna-se essencial não só para atualização da matriz curricular do próprio curso, como também para a formação continuada dos licenciandos-professores. Isso se justifica pelo fato de que muitos alunos, por serem da área de Letras e estudarem a língua materna e/ou uma língua estrangeira, são chamados a traduzir sem conhecimento sobre metodologias, teorias, história e outras especificidades que constituem a tradução como prática profissional. O objetivo deste artigo é fazer um levantamento do olhar do licenciando sobre a tradução no curso de Letras e como este se transforma a partir do contato com teorias da tradução. Esperamos que essas reflexões instiguem um novo olhar de professores e licenciandos sobre a tradução e suas práticas.

PALAVRAS-CHAVE: Estudos da Tradução; Licenciatura; Ensino de Línguas; Leitura e Escrita 
ABSTRACT: Historically anchored in the remnants of the grammar-translation method, translation practice has always been understood as a deviation from the path to fluency in the process of learning a foreign language. However, translation has never been and should not be taken as a teaching methodology, but as a tool in the process of foreign language knowledge and use. Thus, discussing translation in the Languages course, which deals with reading and writing as part of the process of language acquisition, is essential not only for updating the curriculum of the course itself, but also for the continuing education of the undergraduate student-teacher. This is supported by the fact students are usually called to translate without knowing methodologies, theories, history and other specificities that constitute translation as a professional practice as they focus on educational theory and practices only. Therefore, this paper aims to discuss the undergraduate student's view about translation studies as a subject within the Languages undergraduate course and how their perspective changes throughout its practice and research. We expect these reflections provoke a realistic understanding about the need to have translation studies as an essential part of any teachertraining course being it an undergraduate or a graduate one.

KEYWORDS: Translation Studies; Languages Course; Language Teaching; Reading and Writing 


\section{INTRODUÇÃO}

Iniciamos nossas reflexões considerando duas perspectivas que, a nosso ver, são consensuais no discurso da licenciatura em Letras. A primeira refere-se ao fato de que a tradução está sempre e indissociavelmente ligada às metodologias de ensino de línguas, especificamente ao método gramáticatradução. Portanto, a tradução interfere negativamente no processo de aprendizagem da língua alvo, considerando-se as abordagens comunicativas ainda em voga. A segunda trata da concepção equivocada de que a prática tradutória na licenciatura visa à formação do profissional tradutor e não agrega à formação do professor.

O primeiro ponto reforça, nos licenciandos, a mesma ideia que prevalece entre os professores atuantes no ensino fundamental: traduzir é produto, ou seja, uma atividade mecânica que não exige criatividade, mas que preenche os minutos finais da aula e ajuda a disciplinar a turma que precisa entregar o resultado ao professor. Já o segundo, assim como o primeiro, pauta-se sobre o desconhecimento da área, pois em nenhum momento a licenciatura se aproxima das especificidades de um bacharelado em tradução e interpretação. Algumas disciplinas são sim compartilhadas, mas ambos os cursos detêm propósitos claramente distintos e definidos. Ambos os aspectos, entretanto, encontram no desconhecimento sobre a área dos estudos da tradução, o ponto convergente para distanciar a licenciatura das reflexões necessárias promovidas pelo ato de traduzir, entre elas, noções de interculturalidade e processos de produção textual.

A partir desta realidade, torna-se imprescindível desconstruir a ideia de que a tradução é um ato mecânico e descontextualizado ou um método desenvolvido para o ensino de línguas. Para tanto, lembramos que no que se refere às metodologias de ensino de línguas, o método gramática-tradução nunca teve por objetivo ensinar a língua e sim utilizá-la para que, através da tradução literal, o usuário pudesse ter acesso a cânones literários. Traduzir era um meio e não um fim. Paralelamente, trazer os estudos da tradução para a licenciatura não interfere na formação dos licenciandos como professores, em outras palavras, conhecer noções básicas sobre estudos da tradução não os credencia para atuar como profissionais, visto que existem bacharelados específicos na área para formar tradutores.

O conhecimento sobre tradução visa tão somente instrumentalizar o licenciando para incrementar sua prática docente com técnicas e atividades que desenvolvam em seus alunos um olhar cuidadoso para a sua cultura e a do Outro ${ }^{1}$. Nesse sentido, o próprio campo de atuação do egresso em Letras se fortalece, visto que não raro as licenciaturas apontam a tradução como campo de atuação possível sem que o curso ofereça disciplinas pertinentes na área. Sendo assim, a tradução torna o curso mais dinâmico e amplia as áreas de conhecimento e

\footnotetext{
${ }^{1} \mathrm{O}$ "Outro" se refere aqui ao enunciatário e/ou ao leitor final, representado em maiúscula de forma a ter, respeitados, seu lugar e sua função na comunicação. Não se trata aqui de nenhuma relação com teorias da análise do discurso.
} 
atuação dos licenciandos. Paralelamente, as reflexões que emergem da prática tradutória nos permitem mostrar que a tradução é parte inerente do processo ensino-aprendizagem de línguas por ser um espaço privilegiado de reconhecimento e compreensão cultural.

Porém, desconstruir pensamentos intuídos não é tarefa simples, pois estão em jogo aí perspectivas enraizadas, unilaterais e tradicionalistas. É o que temos observado nas duas disciplinas sobre introdução aos estudos da tradução no curso de licenciatura em Letras da universidade tecnológica federal, integrante da matriz curricular desde 2016. Ao mesmo tempo em que notamos interesse e curiosidade dos alunos, observamos também atitudes de resistência, possivelmente vinculadas às ideias expostas no início deste artigo: 'é uma atividade que visa à formação do tradutor e não do professor, e que pode interferir de maneira negativa no meu processo de aquisição da língua alvo e dos meus alunos', sem mencionar o fato de que os resultados das atividades práticas não são aparentes ou rápidos como deveriam (!) ser, pensando que traduzir envolve revisões textuais, pesquisas terminológicas, vocabulário novo, entre outras. Assim, portanto, discutimos o papel da tradução na licenciatura em Letras; o olhar do licenciando sobre a tradução através de experiências em sala de aula da graduação e a presença constante da prática tradutória na vida dos usuários da língua. Esperamos, assim, mostrar que os estudos da tradução propiciam à formação do licenciando em Letras um espaço de discussão privilegiado sobre língua, cultura, (con)texto, leitura e escrita.

\section{A TRADUÇÃO NA LICENCIATURA EM LETRAS: CAMINHOS POSSÍVEIS}

Um grande número de artigos sobre as relações sempre possíveis entre tradução e ensino de línguas acessa esse tema a partir de propostas de atividades geralmente do ensino fundamental (KELLER, 2012; TERRA, 2016; BRANCO, 2009; BRIKS, 2012). Poucos são os que abordam a presença da tradução na licenciatura em Letras, visto que em bacharelados esta relação é, por assim dizer, mais natural. Já pesquisas acadêmicas, dissertações e teses (LAIÑO, 2010; SIGLE, 2014; CHECCHIA; 2002; MELLO, 2012) tendem a discutir a proximidade da tradução com a sala de aula de línguas de forma mais pontual, descrevendo o resultado de experiências desenvolvidas ao longo de todo um semestre de aulas em cursos de graduação. Outras reflexões (FERREIRA, 2014) abordam a tradução como prática em cursos específicos para formação de tradutores, provável razão para muitos leitores associarem prática de tradução apenas com a formação de tradutores.

Independente do caminho, o papel da tradução nas aulas assume foco central, ou seja, é o mecanismo pelo qual as aulas são planejadas e desenvolvidas e através do qual, questões linguísticas, culturais e textuais são analisadas. Nesse contexto, interessa-nos sobremaneira as discussões que propõem a tradução como ferramenta pedagógica (SIGLE, 2014), ou seja, um instrumento que não apenas agrega ao estudo do sistema, mas também do contexto de uso e das questões 
culturais que emergem do processo de conhecimento das línguas. Convém ressaltar que este processo, tecido entre a língua estrangeira e a língua materna constituí também a tradução (MUNDAY, 2002; ZIPSER, 2002; SIGLE, 2014). Isto implica planejamento, leitura cuidadosa, análise, metodologia, revisões de texto, distante da tradução como produto costumeiramente exigido ao final de uma aula de inglês no oitavo ou nono anos do ensino médio, por exemplo. Estão aí caminhos possíveis para explorarmos a tradução na licenciatura em Letras: uma ferramenta adicional na formação continuada do licenciando; uma atividade processual de leitura, análise e produção textual, além de uma abordagem diferenciada sobre as especificidades (inter)culturais que influenciam contextos de produção e recepção textual em qualquer situação.

$\mathrm{Na}$ nossa instituição, as discussões sobre tradução tiveram início em 2013 com apresentações de professores na semana de Letras, o que motivou a criação de um grupo de pesquisa que, para ter aceitação no curso, incluiu 'ensino de línguas' nos seus eixos de pesquisa: estudos da tradução; ensino de línguas e relações entre tradução e ensino de línguas. Desde então, o grupo promove ações de extensão buscando uma identidade voltada à pesquisa sobre estudos tradutórios, na instituição. Dentre estas ações, temos o encontro sobre tradução (EnTrad) que está em sua terceira edição; sete trabalhos de conclusão de curso defendidos, trilhas de pesquisa em estudos tradutórios, além de duas disciplinas obrigatórias: Estudos da Tradução I (panorama histórico, teórico e prático de tradução) e II (ênfase em tradução literária). Lembrando Paulo Ottoni (2005, p. 71), podemos afirmar que em meio às resistências sobre o papel da tradução em uma licenciatura, observamos que a oferta dessas disciplinas alcança o interesse de muitos alunos e amplia suas oportunidades profissionais paralelas à atividade docente.

Assim, o trabalho inicial no curso foi o de convencimento dos alunos de que mesmo no segundo período e com níveis distintos de conhecimento de língua, praticar tradução não só poderia agregar conhecimento profissional como também mostrar que barreiras são ilusórias quando estamos abertos ao conhecimento. $\mathrm{O}$ passo seguinte foi mostrar o alcance da tradução através de gêneros textuais diversos, para além dos resumos científicos, Letras de música e legendagem de vídeos para o youtube ou netflix. Dessa maneira, foi possível rever o conceito comumente associado à tradução que é "passar uma mensagem, de forma literal e equivalente, de uma língua para outra". A nosso ver, tal ideia implica um movimento controlado, de relativo apagamento, similar aos brinquedos infantis nos quais devemos encaixar uma peça numa superfície exatamente com a mesma forma, sugerindo um modo de traduzir em que diferentes contornos culturais são similares entre si e, portanto, não oferecem resistência. É uma visão possível, mas que traz consigo uma percepção reducionista para um processo muito mais complexo do que se imagina.

Buscamos, portanto, mostrar a tradução como um movimento mais orgânico e maleável de ir e vir de encontro ao Outro e de volta a si mesmo, conforme Coracini (2007). Acreditamos que é essa a dinâmica que deve sustentar a prática tradutória na licenciatura, primeiro em razão de o curso de Letras evidenciar a questão da interculturalidade e também pelo fato de que o objeto 
comum a tradução e a formação do professor em Letras é justamente a linguagem em uso. A noção desse movimento, por si só, auxilia ainda a desconstruir mitos relacionados à tradução, como por exemplo, a noção de que somente o conhecimento linguístico sustenta a prática tradutória ou ainda que a tradução interfira, negativamente, no processo de aquisição de uma segunda língua.

\section{O LICENCIANDO EM LETRAS E A TRADUÇÃO: EXPERIÊNCIAS POSSÍVEIS}

Experimente perguntar a professores e alunos dos cursos de Letras como eles conceituam tradução. A grande maioria certamente dirá que traduzir é a tarefa de passar um texto de uma língua pra outra e, assim, unem-se a outra grande parcela, a do público leigo e que precisa dos tradutores, para quem tradução é sinônimo de: "versão; expressão/conversão de ideias; não perder a essência do texto; transcrição, transposição, passagem, transferência de sentidos e de informações, transformação, decodificação, reprodução, domínio de línguas, transmissão". Fica implícita aí a condição de que pensamos de maneira isonômica, compreendemos e visualizamos situações de maneira igual, que temos questões culturais idênticas, mesmo com experiências de vida e de leituras as mais diversas. É uma falsa sensação de equivalência que ratifica um conceito e prática tradutória inteiramente estruturalista.

Não é à toa, portanto, que em meio acadêmico a inserção da tradução na Letras é vista com certa desconfiança, pois para um momento no qual interagem a necessidade de abordagens comunicativas e as especificidades de uma era pósmétodo, qualquer resquício de bases estruturalista, como a literalidade ou a equivalência um-pra-um, entra em conflito com perspectivas de cunho sócio histórico prevalecentes nas licenciaturas, em razão da dinâmica das línguas e suas nuances culturais. Como a tradução está irrevogavelmente vinculada à ideia de ser uma metodologia de ensino de línguas, mudar padrões de pensamento em relação ao conceito histórico da tradução é um desafio. Mas fato é que a tradução jamais preconizou uma metodologia para o ensino de línguas, nem tampouco o próprio método gramática-tradução tinha como objetivo ensinar uma nova língua ou fazer com que sujeitos se comunicassem através dela. O objetivo dessa metodologia era tão somente facilitar o acesso a cânones literários, valendo-se da tradução como meio para favorecer a compreensão dos textos clássicos.

Como o próprio nome diz esse método parte do princípio de que as línguas têm os mesmos sistemas de funcionamento, portanto, são equivalentes sintática, semântica e pragmaticamente, reduzindo a atividade tradutória à busca por sistemas similares e uma tradução literal. Como essa tarefa demanda conhecimento de línguas distintas, dominar a tradução significa dominar o funcionamento do idioma envolvido, isto é, a gramática na sua acepção mais estruturalista: gramática entendida como sistema. Nessa perspectiva, a prática tradutória representa um fim em si mesma, sustentada pela ideia de que frases, palavras ou expressões sempre encontram equivalentes em forma e significado 
em qualquer outra língua. Basta dominar o vocabulário e a estrutura do par de línguas para alcançar o objetivo proposto: ler a obra estrangeira em vez de se comunicar entre línguas. Com efeito, não é difícil entender porque a tradução é vista como vilã no processo de ensino-aprendizagem de línguas. Portanto, as visões contrárias ao uso da tradução em sala de aula tomaram uma proporção até hoje difícil de ser alterada, reação essa extensiva à própria formação docente em cursos de licenciatura tanto presenciais quanto na modalidade $\mathrm{EaD}$.

Para exemplificar nosso argumento, tecemos algumas considerações a respeito da relação entre alunos do curso de licenciatura em Letras inglês da Universidade Tecnológica Federal do Paraná (UTFPR) e a prática de tradução na disciplina 'introdução aos estudos da tradução' e nos grupos de pesquisa em tradução jornalística e literária. Cabe ressaltar que a disciplina introdutória de tradução foi prevista nos estágios iniciais do curso: i) prevendo um público relativamente familiarizado com a língua inglesa, ou seja, alunos com nível intermediário de conhecimento de língua e ii) o eixo estrutural denominado português para falantes de outras línguas (PFOL) em razão de as práticas previstas em sala de aula estarem inseridas no movimento inglês $<$ português. A ementa da disciplina e dos grupos de pesquisa tem como objetivo ampliar o conhecimento e atuação dos licenciandos oferecendo-lhes a possibilidade de uma profissão paralela à docência e/ou do uso consciente de uma ferramenta a mais para o desenvolvimento do processo de ensino-aprendizagem de línguas.

Para investigar a perspectiva dos licenciandos, elaboramos um questionário composto de cinco perguntas, aplicado no início do semestre para as disciplinas mencionadas: “o que significa 'tradução' para você?'; 'você já exerceu a função de tradutor?'; 'qual material traduziu e para quem?'; 'em sua opinião, é importante estudar a 'tradução' na Letras?' e 'ao pensar em 'tradução' quais palavras vem a sua mente - cite ao menos três (3).' Ao final do semestre, replicamos as perguntas sobre conceito de tradução e palavras-chave para os alunos, totalizando 30 respondentes. Em seguida, analisamos e agrupamos as respostas considerando palavras-chave nas respostas, o que nos mostrou alguns eixos temáticos, apresentados e comentados a seguir.

\section{LICENCIANDOS E TRADUÇÃO: RESPOSTAS POSSÍVEIS}

Encontrar uma resposta ou conceito para tradução não é tarefa simples, nem por isso deixamos de perguntar aos alunos qual seria sua ideia e concepção para a tradução. Questioná-los sobre algo tão complexo, logo de início, nos garantiu uma visão relativamente isenta de embasamento teórico e, ao analisar as respostas, observamos que constituíam 4 grandes eixos, denominados por nós: cultura, literalidade, sentido e globalização.

O eixo 'cultura' uniu 12 respostas que relacionam tradução com 'aproximação', 'adequação', 'troca', 'compartilhamento intercultural' e 'ponte entre povos', esta última especificamente com quatro menções explícitas. Já o eixo 'literalidade' foi o que obteve o maior número de respostas, 22, associando a 
prática tradutória a termos como: 'transmissão', 'decodificação', 'transposição', 'transferência', 'transcrição de uma língua para outra'. Estas respostas confirmam uma perspectiva tradicionalista relativamente comum sobre os estudos da tradução como área acadêmica e profissional, a qual vincula o ato de traduzir unicamente ao domínio do par de línguas em questão. O eixo 'sentido', por outro lado, obteve apenas duas respostas que associaram a ideia de tradução com 'transferência de ideias, conceitos, emoção, efeito' sobre o leitor final, enquanto o eixo 'globalização' vinculou $\mathrm{o}$ ato de traduzir com a 'comunicação', 'compartilhamento de conhecimento e cultura', além de 'mensagens entre pessoas do mundo inteiro'. Este último eixo temático demonstra que a ideia de traduzir responde basicamente à necessidade de se fazer entender em outra língua, voltando mais uma vez ao que parece ser condição única para se traduzir, na opinião dos alunos: dominar o par de línguas em questão. Os alunos aparentemente isolam outras questões que inevitavelmente influenciam o ato tradutório como o próprio tradutor, o leitor-final, suas pressuposições, questões de estilo, estratégias, alterações de ordem semântica, sintática e pragmática.

As respostas para a segunda pergunta (você já exerceu a função de tradutor?) corroboraram uma realidade que não nos surpreendeu: 26 alunos informaram já ter exercido a função de tradutor ao traduzir músicas (12 respondentes); artigos acadêmicos (8 respondentes) e resumos $>$ abstracts (7 respondentes). Demais materiais tais como vídeos, contratos, monografias, blogs, poesia, contos, textos de livros didáticos, conversas, frases em camisetas, legendas, por exemplo, foram mencionados uma vez, enquanto 13 alunos afirmaram nunca terem traduzido nada. A nosso ver, conhecer os materiais possivelmente já traduzidos reafirma o fato de a tradução se constituir uma prática restrita ao eixo acadêmico (artigos, resumos-abstracts) e entretenimento (músicas) sem que os alunos tenham consciência da área como profissão, como pesquisa e processo, reiterando a necessidade de trazer essas discussões para sala de aula e oferecer aos alunos noções teóricas e práticas diversas. Porém, no início do semestre, os alunos não tem ciência do que a disciplina introdutória pode oferecer. Sendo assim, a pergunta 4 investigou a importância de se estudar sobre tradução no curso de Letras e pediu que os alunos justificassem suas respostas. Novamente, ao analisarmos as respostas, 3 eixos puderam ser identificados, a saber: profissão de tradutor; formação-prática de sala de aula e conhecimento pessoal.

O primeiro sobre a profissão, com 5 respostas, vincula a tradução ao interesse e possibilidade de se tornar profissional na área. O segundo, com 30 respostas, relaciona a tradução como complemento da carreira docente $(15 \mathrm{x})$ e ferramenta de auxílio ao professor (4x) para melhorar o desempenho em sala (8x). Três outras respostas mencionam também o fato de a tradução agregar valor ao curso e auxiliar a compreensão e domínio da língua inglesa, por estar presente em muitos materiais de leitura no curso. Por fim, o terceiro eixo apresenta a tradução como uma área de conhecimento que favorece a observação e compreensão de questões interculturais. Neste eixo, ressaltamos três respostas mencionadas de forma recorrente: "para aprender uma nova língua/pensar em inglês"; "facilita a comunicação" e "tradução é comunicação". 
A última pergunta do questionário solicitou aos alunos, no mínimo três palavras-chave relacionadas à tradução. Em consonância com as respostas anteriores, quatro eixos foram observados: cultura; sentido; literalidade e profissão/ensino. No eixo 'cultura', quatro palavras obtiveram destaque: cultura (10x); contexto (4x); comunicação (7x) e ideias compartilhadas (3x). Já o eixo 'sentido' trouxe à tona: interpretação $(6 \mathrm{x})$; adaptação, transmissão e recriação $(4 \mathrm{x}$ cada); compreensão ( $3 \mathrm{x})$ e sentido/significado ( $7 \mathrm{x})$. O eixo 'literalidade' apontou os seguintes resultados: gramática e transcrição ( $2 \mathrm{x}$ cada) e fidelidade $(3 \mathrm{x})$, enquanto o último eixo 'profissão/ensino' foi o que apontou maior diversidade de palavras listadas; destas, as recorrentes foram: profissão (3x); línguas (11x) e estudo e conhecimento (4x cada). A diversidade de palavras listadas pelos alunos, levando em consideração o início do semestre, demonstra a pluralidade de caminhos associados à tradução, com ênfase à perspectiva que tradicionalmente coloca a tradução como vilã no processo de ensino-aquisição de línguas: traduzir é manter, com fidelidade e literalidade, a mensagem e o sentido do texto-fonte. Acreditamos que os alunos que mencionam palavras como cultura, contexto e comunicação podem ser os que já trazem um conhecimento mais amplo sobre o idioma e que já tenham lido ou ouvido sobre a profissão por interesse pessoal.

Ao final do semestre letivo, replicamos as perguntas 1 e 5 a fim de compreender se a visão dos alunos sobre a disciplina sofreria alguma alteração (para melhor ou pior) após terem sido expostos a história, teoria, prática e pesquisa em sala de aula e nos grupos específicos. Em relação às palavras-chave, os alunos associaram o eixo cultura com os seguintes termos: troca/intercâmbio $(2 x)$, comunicação $(6 x)$, cultura $(9 x)$, contexto $(4 x)$, integração, regionalização, ponte e conexão (1 resposta cada). No eixo sentido, os alunos listam termos como mensagem/conteúdo (3x), interpretação (3x), significado (3x), naturalidade (3x), público-alvo (3x), criatividade (3x) e reinterpretação. Percebe-se aqui uma preocupação com o público-alvo e uma abertura para as possibilidades de tradução em diferentes contextos. As palavras criatividade, transformação, adaptação, originalidade e reinterpretação podem ser um rompimento com a concepção tradicional (e possivelmente equivocada) de que o tradutor não pode ter liberdade no processo de tradução em função do comprometimento com o autor da obra original.

Curiosamente o eixo literalidade teve o número de termos reduzidos para equivalência (1x), adequação (1x), signos (1x), fidelidade (1x) e literalidade (3x). Isso pode ser interpretado como indicativo de que os alunos se desvincularam de uma visão mais tradicional de tradução e ampliaram a visão para um maior número de possibilidades (como pôde ser observado no eixo sentido) no processo tradutório, sem a preocupação inicial de fidelidade ao texto. $\mathrm{O}$ quarto eixo, relacionado à parte de profissão/formação/ensino atrelou termos como conhecimento (3x), esforço (3x), dedicação (3x), língua (3x), localização (3x) e responsabilidade (2x). Esses termos reforçam a necessidade de qualificação do tradutor e a necessidade de um grande comprometimento com a tarefa de traduzir.

As respostas dos alunos para a primeira pergunta (o que significa tradução para você?) neste segundo momento, já ampliam a visão de uma mera transposição ou 'ponte' de palavras entre culturas para a necessidade de entender 
o contexto cultural no qual a obra está inserida, fazendo adequações no âmbito de questões sociais, culturais, regionais. Dentre as 13 respostas obtidas e classificadas no eixo cultura, os alunos reconhecem a necessidade de levar em consideração o público-alvo, o contexto e a naturalidade da língua, o que vai muito além da mera busca por equivalentes. Os alunos também sinalizaram a possibilidade adequar a obra ao contexto no qual ele está traduzido, o que está diretamente ligado com concepções contemporâneas de tradução.

Apesar dessa ampliação de perspectiva observada no eixo cultura, obtivemos 5 respostas que ainda associam o processo tradutório com o eixo literalidade mostrando uma preocupação com a preservação do significado de expressões linguísticas, a transmissão do conteúdo mantendo a essência/intuito do original. Duas respostas utilizam o termo fidelidade, o que ainda mostra uma visão conservadora sobre o processo tradutório e papel do tradutor, mesmo após ter contato com teorias contemporâneas de tradução.

No eixo intitulado sentido/leitura/pesquisa, 6 respostas apontam para a tradução como forma de arte, na qual se produz uma nova história. Aqui os alunos sinalizam o reconhecimento de que o trabalho do tradutor exige muita leitura e fundamentação teórica, um processo que envolve brainstorming e pesquisa. Isso é um indicativo de conscientização de ter conhecimento da línguaalvo não é suficiente para se traduzir. Isso foi reforçado pela menção de que para reescrever e recriar um texto é necessário conhecer seus signos, símbolos e até mesmo a musicalidade do texto, demandando um conhecimento que vai além da língua em si.

O eixo globalização/comunicação, com 6 respostas, abordou a tradução como a chave para democratizar a cultura e informação. A tradução também foi abordada como um meio de transmissão de conhecimentos, um ato comunicativo que consiste em passar informações de uma língua para outra, possibilitando que pessoas com diferentes línguas possam acessar um universo de livros, filmes e séries do mundo todo. Por fim, temos um quinto eixo que coloca o tradutor/leitor em perspectiva. Neste eixo a tradução é definida como um processo trabalhoso que exige a mente aberta por parte do tradutor, já que cabe a ele tornar um conteúdo acessível ao seu público-alvo. A tradução aqui assume o papel de apresentar um universo cultural novo para outras realidades, podendo trazer aspectos culturais do TF ou o adequando ao contexto no qual ele está sendo traduzido.

Comparando as respostas das duas etapas, percebe-se que o contato com teorias da tradução e a prática orientada ampliou a percepção dos alunos sobre a área de estudos em si e sobre a importância do tradutor e do público-alvo durante o processo. Os eixos sentido e profissão/ensino foram complementados com mais palavras-chave, enquanto o eixo da literalidade, que pode ser associado com concepções mais conservadoras sobre tradução foi menos enfatizado na segunda etapa de coleta de dados. Este pode ser um indicativo de que, apesar de ainda aparecerem respostas que descrevem o ato de traduzir como a mera transcrição de expressões de uma língua para outra preservando o sentido do original, e enfatizando termos como literalidade e fidelidade, houve uma ampliação da visão 
dos alunos em relação a esta área de estudos e ao papel do tradutor durante o processo tradutório.

\section{A TRADUÇÃO EM TODO O LUGAR, INCLUSIVE NA LETRAS: REFLEXÕES POSSÍVEIS}

Mudar o paradigma da prática tradutória é imprescindível, pois conforme Sobral (2008) traduzimos tudo e a todo o momento: do nosso pensamento em um artigo até nossos planos em aulas efetivas. Traduzir é prática inerente à vida e se faz diferenciada cultural e contextualmente, entre os sujeitos envolvidos e do grau de compartilhamento do(s) assunto(s) em discussão. Entretanto, o que se vê nos cursos de Letras aponta dois caminhos mutuamente excludentes: ou a tradução é persona non grata por interferir negativamente no processo de aquisição de línguas ou por não ter relações com a prática docente.

Sobral (2008) comenta sobre o fato de a tradução ser em si mesma comunicação. Nord (1991), teórica da tradução e tradutora propõe o conceito de tradução como ato comunicativo voltado a um leitor sempre pensado junto e como fim do processo tradutório. Zipser (2002) defende igualmente a tradução como comunicação, caminho seguido por Sigle (2014), Rostock (2016) e Laiño (2010). Nesse sentido, a tradução não é um acontecimento isolado dos sujeitos envolvidos (autor/leitor/tradutor), propósitos (funções pensadas para o texto-fonte e texto-alvo) e dinâmicas da língua (situações e condições de produção e de recepção textuais). Não há mais lugar, desde a instituição dos estudos tradutórios na academia, para a literalidade prevista pelo método gramática-tradução, caso contrário não haveria razão para reflexões incessantes sobre o processo de ensino/aquisição de línguas, visto que os interlocutores se entenderiam perfeitamente pondo fim ao mito da Babel, tão conhecido pelos alunos da Letras.

Dizer o mesmo aos outros, seguindo o pensamento de Sobral (2008) é, sobretudo pensar no que se diz, como se diz, que função tem o que é dito, no contexto, no momento, na intenção, no efeito desejado sobre o interlocutor. Dizer o mesmo aos outros implica um olhar diferente do singular, do homogêneo, pelo simples fato de que as línguas e seus usuários (sejam eles interlocutores na conversação ou leitores finais de um texto) não são iguais, pensam e tem experiências de vida distintas, fazem parte de grupos sociais e culturais diversões e, portanto, podem dizer o mesmo a outros de diversas maneiras, pois constroem sentidos e significados das maneiras mais diversas segundo suas próprias maneiras de entender o mundo. Como então podemos continuar associando o ato de traduzir à literalidade pressuposta pelo método gramática tradução? Os alunos em sala não pensam de maneira igual, nem tampouco é possível dar uma aula sobre um determinado assunto da mesma maneira. O público que nos ouve nem sempre é o mesmo e esse público nem sempre compartilha do que dizemos, em função de graus de conhecimento diferentes e porque constrói sentidos por caminhos e associações diversas das nossas. Dizer o mesmo aos outros não é, portanto, um processo linear, mas sim um ato comunicativo tão cambiável e 
dinâmico como o é a própria língua. E sendo um processo ativo, não pode simplesmente ser um método estrutural, delimitado e compartimentado.

\section{CONSIDERAÇÕES FINAIS}

Neste artigo buscamos refletir sobre caminhos de inserção dos estudos tradutórios nos cursos de licenciatura em Letras. Sendo exclusivamente uma área voltada a formação de professores, os estudos tradutórios não tem vez, pois não formam professores e sim tradutores. Esses desvios de entendimento são resultados não só da compreensão equivocada sobre o que seja ou constituía o processo tradutório, como também do equívoco ao pensar que traduzir em sala de aula de língua estrangeira bloqueie o "pensamento" diretivo na língua em estudo atrapalhando a fluência do aluno, e que esta disciplina visa fazer do licenciado em Letras um tradutor.

De fato, se pensarmos de forma ampliada, somos todos tradutores em todas as áreas de conhecimento nas quais atuamos, considerando-se a tradução não como um produto, isto é, uma atividade restrita a transferência de estruturas gramaticais (sintáticas e semânticas) de um texto em uma determinada língua para uma outra. Traduzir é antes de tudo, representar pensamentos, ações, modos de vida, de pensamento, experiências de vida que constituem todo o aparato cultural intrínseco ao ensino-aprendizado de outra língua, traduzir é representar o conteúdo de sua disciplina no quadro, é parafrasear uma instrução que o aluno não tenha compreendido, é explicar o que significa determinada palavra em seus contextos de uso, é transferir oi pensamento em escrita ou oralidades. Ainda que alguns teóricos discordem dessa possibilidade pela amplitude exagerada que a tradução adquire, pode ser esta uma maneira de trazê-las para o spotlight, de fomentar reflexões, discussões e paralelos entre as ações de professores de línguas e tradutores.

Não raro presenciamos alunos de licenciatura traduzindo "profissionalmente" ou, acreditando que traduzir é apenas ler a frase com cuidado antes de levá-la para o campo da língua estrangeira, não raro nesse processo acredita-se que ao encontrar um equivalente é sinal de uma boa escolha, de uma tradução de qualidade. Não raro ainda esses mesmos alunos-tradutores, travam no meio do caminho pelas dificuldades que o texto, idioma, palavra, sentido, contexto, escrita apresentam e, aos poucos, vão aprendendo do modo mais difícil que traduzir é uma área de estudo e trabalho muito mais complexa do que se pensava e que a competência na língua estrangeira que parecia suficiente, não o é mais, pois as competências do tradutor perpassam os sentidos do texto, nuances semióticas, estilísticas e pragmáticas que também são estudadas na licenciatura.

Assim, buscamos fazer pensar em caminhos para um lugar da tradução nos cursos de licenciatura na prática, na reflexão, mas de alguma maneira que faça os alunos reverem sua postura com relação aos estudos tradutórios, com relação à prática em si dos profissionais tradutores e principalmente que encontrem na tradução uma aliada ao incremento das suas aulas, das análises de textos com os 
alunos, dos estudos de gênero, da produção textual, até mesmo da oralidade instrumentalizando o aluno a negociar sentidos, informações em práticas de oralidade. Traduzir não pode mais ser vista como uma tarefa qualquer, que qualquer um faz, de qualquer maneira - ela tem propósito, demanda competências, favorece e amplia reflexões sobre uso da língua, sobre estudo das línguas, sobre culturas e suas relações interculturais, ela mostra que tem e merece um lugar ao sol.

As respostas compiladas na tabela nos levam a pensar na necessidade de seguirmos insistindo em oferecer as atividades teóricas e práticas aos alunos da licenciatura em Letras por uma razão que, a nosso ver, prevalece sobre qualquer outra: traduzir é comunicar, comunicação é a essência do curso de Letras, seja bacharelado ou licenciatura e para nos comunicarmos utilizamos, seja como tradutores e/ou professores, uma ferramenta em comum: a língua, sustentada e influenciada por todas as suas condições individuais, sociais, históricas e culturais.

\section{REFERÊNCIAS}

BRANCO, Sinara de Oliveira. Teorias da tradução e o ensino de língua estrangeira. Horizontes de Linguística Aplicada, v. 8, n. 2, p. 185-199, 2009.

BRIKS, Fábio Júlio Pereira. Tradução: ferramenta eficaz no ensino-aprendizagem de línguas estrangeiras para o aluno do ensino superior. Belas Infiéis, v. 1, n. 1, p. 153-167, 2012.

CHECCHIA, R.L.T. O retorno do que nunca foi: O papel da tradução no ensino do inglês como língua estrangeira. Brasília. Dissertação de Mestrado, Universidade de Brasília, Instituto de Letras, Departamento de Línguas Estrangeiras e Tradução. 2002.

CORACINI, Maria José R. F. A celebração do outro. Campinas: Mercado de Letras, 2017.

COSTA, W. Carlos. "Tradução e ensino de línguas". In: BOHN H. Inácio, Vandresen, P. Tópicos de Linguística Aplicada ao ensino de línguas estrangeiras. Florianópolis: Editora da UFSC, 1988.

FERREIRA, Alice Maria de Araújo et alii. A tradução na sala de aula: ensaios de teoria e pratica de tradução. Brasília: editora da UnB, 2014.

KELLER, Maria Cristina. O uso da tradução no ensino de línguas estrangeiras. SELEP, v. 2, 2012. Disponível em: <http://periodicos.unesc.net/selep/ article/view/632/635>. Acesso em: 14 jun. 2017.

LAIÑO, Maria José. Multiculturalismo: propostas de recontextualizações de fatos culturais na tradução de textos em livros didáticos. Dissertação apresentada ao Programa de Pós-Graduação em Estudos da Tradução da 
Universidade Federal de Santa Catarina. Florianópolis, 2010. Disponível em: $<$ http://ppget.posgrad.ufsc.br/>. Acesso em: 17 mar. 2017.

MELO, Noemi Teles de. Texto e contexto na construção de sentidos: a tradução em sala de aula de LE. Dissertação apresentada ao Programa de Pós-Graduação em Estudos da Tradução da Universidade Federal de Santa Catarina. Florianópolis, 2012. Disponível em: < http://ppget.posgrad.ufsc.br/>. Acesso em: 12 mar. 2017.

MUNDAY, Jeremy. Introducing Translation Studies: theories and application. NY: Routledge, 2002.

NORD, Christiane Nord. Text Analysis in Translation. Amsterdam, Atlanta, GA: Rodopi, 1991. Tradução Christiane Nord e Penelope Sparrow.

OTTONI, Paulo. Tradução manifesta: doublebind e acontecimento. Campinas: Editora da Unicamp; São Paulo: EDUSP, 2005.

SIGLE, Cassia. Tradução Pedagógica: A influência de textos paralelos em atividades tradutórias no contexto de ensino-aprendizagem de Língua Estrangeira. Dissertação apresentada ao Programa de Pós-Graduação em Estudos da Tradução da Universidade Federal de Santa Catarina. Florianópolis, 2014. Disponível em:

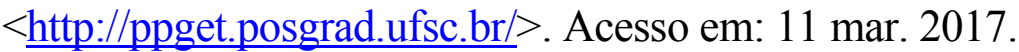

SOBRAL, Adail. Dizer o mesmo aos outros: ensaios sobre tradução. São Paulo: Special Book Services Livraria, 2008.

TERRA, Márcia Regina. Tradução \& aprendizado de língua estrangeira: o ponto de vista do aluno. Trabalhos em Linguística Aplicada. 2010, vol. 49, n. 1, pp. 6985. Acesso em: 25 de jun. de 2017. Disponível em: $<$ http://www.scielo.br/scielo.php?pid=S0103-18132010000100006\&tlng $=\mathrm{pt}$ \&script $=$ sci abstract $>$.

ZIPSER, Meta Elisabeth. Do fato a reportagem: as diferenças de enfoque e a tradução como representação cultural. Tese apresentada ao Departamento de Letras Modernas da Faculdade de Filosofia, Letras e Ciências Humanas da Universidade de São Paulo, São Paulo, 2002. Disponível em: $<$ http://ppget.posgrad.ufsc.br/>. Acesso em: 12 mar. 2017.

Silvana Ayub Polchlopek Sil-in-SC@uol.com.br

Flávia Azevedo FlaviaUTF@gmail.com

Recebido em: 14/9/2017

Aceito em: 6/2/2018

Publicado em Abril de 2018 